\title{
A possibilidade de exclusão do condômino antissocial no condomínio edilício
}

\author{
The possibility of exclusion an anti-social tenant in a building condominium \\ La posibilidad de exclusión del condominio antisocial del condominio del edificio
}

Recebido: 19/12/2021 | Revisado: 27/12/2021 | Aceito: 31/12/2021 | Publicado: 08/01/2022

Dandara Herdi Polastri Rebello

ORCID: https://orcid.org/0000-0003-4475-320X

Faculdade Presbiteriana Mackenzie Rio, Brasil

E-mail: dandaraherdi@hotmail.com

\begin{abstract}
Resumo
Este trabalho tem como proposta analisar através da doutrina e jurisprudência se é possível a exclusão de um condômino considerado antissocial em razão de reiterado comportamento antissocial à vista das limitações impostas pelo direito de propriedade, seja em razão da violação à função social, ou por vedação ao abuso do direito, ou, ainda, em prol do direito de vizinhança. Nos condomínios edilícios, dada a proximidade das unidades autônomas e do necessário convívio nas áreas comuns, devem ser adotadas medidas que prezem pela paz entre os vizinhos, que são estabelecidas pelas normas condominiais (Convenção e Regimento Interno) que buscam manter a paz e harmonia na vida condominial. Nesse contexto, o presente artigo busca analisar se, diante de comportamentos graves e reiterados, seria possível a exclusão do condômino antissocial do condomínio edilício. A cerne do presente artigo é expor as limitações do direito de propriedade em razão de sua função social, abordar o conceito de "condômino antissocial", abordar sobre a normas condominiais e analisar a possibilidade de sua exclusão do condomínio edilício, através de dispositivos legais, posicionamentos doutrinários e decisões judiciais que versam sobre a matéria, a fim de embasar as informações coletadas e aqui apresentadas.

Palavras-chave: Direito de Propriedade; Direito de Vizinhança; Condomínio edilício; Normas condominiais; Exclusão do condômino antissocial.

Abstract

This work proposes to analyze, through doctrine and jurisprudence, whether it is possible to exclude a unit owner who is considered antisocial due to repeated antisocial behavior in view of the limitations imposed by the right to property, whether due to violation of the social function, or for prohibition of the abuse of the right, or even in favor of the neighborhood right. In building condominiums, given the proximity of the autonomous units and the necessary coexistence in common areas, measures must be adopted that promote peace between neighbors, which are established by condominium rules (Convention and Internal Regulation) that seek to maintain peace and harmony in the condominium life. In this context, this article seeks to analyze whether, in the face of serious and repeated behavior, it would be possible to exclude the antisocial condominium from the building condominium. The essence of this article is to expose the limitations of property rights due to its social function, address the concept of "antisocial joint owner", address condominium rules and analyze the possibility of their exclusion from the building condominium, through legal provisions, doctrinal positions and court decisions that deal with the matter, in order to support the information collected and presented here.
\end{abstract}

Keywords: Property Law; Neighborhood Law; Building Condominium; Condominium rules; Exclusion of the antisocial condominium.

\section{Resumen}

Este trabajo se propone analizar, a través de la doctrina y la jurisprudencia, si es posible excluir a un propietario que sea considerado antisocial por reiteradas conductas antisociales ante las limitaciones que impone el derecho a la propiedad, ya sea por vulneración de la función social, o por la prohibición del abuso del derecho, o incluso a favor del derecho vecinal. En la edificación de condominios, dada la proximidad de las unidades autónomas y la necesaria convivencia en las áreas comunes, se deben adoptar medidas que promuevan la paz entre vecinos, las cuales se establecen mediante normas de condominio (Convención y Reglamento Interno) que buscan mantener la paz y la armonía en el vida en condominio. En este contexto, este artículo busca analizar si, ante conductas graves y reiteradas, sería posible excluir al condominio antisocial del condominio edificio. La esencia de este artículo es exponer las limitaciones de los derechos de propiedad por su función social, abordar el concepto de "condominio antisocial", abordar las reglas del condominio y analizar la posibilidad de su exclusión del edificio condominio, a través de disposiciones legales, posiciones doctrinales y decisiones judiciales que se ocupan del asunto, con el fin de respaldar la información recopilada y presentada aquí. 
Palabras clave: Derecho Inmobiliario; Derecho Vecinal; Edificio Condominio; Reglas del condominio; Exclusión del condominio antisocial.

\section{Introdução}

O dia a dia em um condomínio traz diversos desafios em razão das diferenças de classes, educação, diferenças culturais, religiosas, dentre outras, que acabam podendo colidir em algum momento.

Os condomínios edilícios possuem regras a serem respeitadas e o objeto do presente artigo é o estudo acerca da problemática sobre a possibilidade de exclusão do condômino que mora em condomínio edilício, por reiterado comportamento antissocial, à vista das limitações impostas pelo direito de propriedade em razão da função social, da garantia do direito de vizinhança ou da vedação ao abuso do direito, principalmente, pelo fato de tal possibilidade inexistir na lei.

A questão abordada no presente artigo deve-se à importância social da questão, principalmente em época de pandemia, na qual se tornou necessário o isolamento social, obrigando as pessoas a ficarem e até trabalharem de suas residências, o que por consequência, pode acabar por aumentar as discussões que envolvem o direito de vizinhança e os problemas gerados pela convivência e proximidade, bem como pelo fato de inexistir entendimento unânime na doutrina e na jurisprudência sobre o tema.

Existem comportamentos que ultrapassam os limites da razoabilidade e do bom senso, configurando verdadeiras afrontas aos costumes, a moral e a ética. São situações em que a simples aplicação de multa ou restrição de direitos, conforme estipula a convenção e regimento interno do condomínio, não são capazes de inibir a reincidência na infração, acabando por prejudicar o sossego, a saúde, a vida e a segurança dos demais moradores do condomínio.

Nesse contexto, surge a discussão sobre a possibilidade de exclusão do condômino por reiterado comportamento antissocial, como forma de reestabelecer a harmonia e a paz condominial, diante dos conflitos de vizinhança, abusos do direito e violações à função social da propriedade privada.

Dessa forma, o presente trabalho busca expor e responder todos os aspectos sobre a possibilidade de exclusão do condômino antissocial, apesar de inexistir lei prevendo tal possibilidade.

\section{Metodologia}

O presente artigo tem como objetivo, expor e responder acerca da possibilidade de exclusão do condômino considerado antissocial em razão da reiteração de condutas lesivas e essa avaliação será realizada através do ponto de vista jurisprudencial e doutrinário.

A metodologia adotada no presente estudo é exploratória, de natureza qualitativa, aplicada através do método dedutivo e de pesquisa bibliográfica.

De acordo com Marconi e Lakatos (2002), a pesquisa bibliográfica, tem o objetivo de explorar problemas a partir de pressupostos teóricos sobre a abordagem do tema em pesquisas científicas, de forma que esta referência "não é mera repetição do que já foi dito ou escrito sobre certo assunto, mas propicia o exame de um tema sob novo enfoque ou abordagem, chegando a conclusões inovadoras".

Segundo Almeida (2017) o método dedutivo, aplicado no presente artigo, parte das teorias e leis e na maioria das vezes prevê a ocorrência dos fenômenos particulares (conexão descendente); se o conhecimento é insuficiente para explicar um fenômeno, surge o problema; para expressar as dificuldades do problema são formuladas hipóteses; das hipóteses deduzem-se consequências a serem testadas ou falseadas.

Para responder a questão sobre a possibilidade de exclusão do condômino antissocial, o presente artigo compõe-se de quatro tópicos. O primeiro aborda questões sobre o direito de propriedade e os limites do direito de vizinhança, o segundo tópico define o que é o instituto do condomínio edilício e define quais são os seus regramentos, o terceiro tópico por sua vez, esclarece 
através da conceituação de inúmeros autores o que se considera como condômino antissocial e por fim, o tópico quatro se propõe a esclarecer se é possível ou não a exclusão do condômino antissocial, através da análise da jurisprudência dos tribunais, uma vez que inexiste lei prevendo tal possibilidade.

O conhecimento adquirido através do presente artigo auxiliará no esclarecimento aos moradores dos condomínios edilícios, síndicos e operadores do direito sobre as normas existentes no tocante ao tema e responderá a questão sobre se é possível ou não a exclusão do condômino antissocial, uma vez que não existe lei prevendo a possibilidade de exclusão.

\section{Resultados e Discussão}

\subsection{Direito de propriedade e o direito de vizinhança}

A legislação brasileira exige o atendimento à função social da propriedade, não bastando apenas que a utilização do bem para moradia, para exploração econômica ou para a prestação de um serviço, impõe-se uma utilização adequada, que seja de acordo com um padrão ético de comportamento, segundo a boa-fé objetiva, sob pena de configurar abuso de direito.

Segundo Gonçalves (2016), embora a propriedade possua garantia constitucional, ela é dinâmica e vem passando por um processo de intensa relativização, tendo os seus parâmetros limitados pela legislação. Ademais, a propriedade é fruto do sentimento de posse, construída a partir da noção de "assenhoramento" do bem, pouco importando o grau de conhecimento do indivíduo.

Com base no Código Civil, pode-se interpretar que o direito de propriedade é o poder jurídico atribuído a um titular de usar, gozar e dispor de um bem corpóreo ou incorpóreo, em sua totalidade e dentro das limitações estabelecidas em lei, assim como o direito de reivindicá-lo de quem injustamente o detenha.

Nesse passo, a propriedade não deve atender exclusivamente aos interesses do indivíduo-proprietário, mas sim da sociedade que compartilha o espaço.

Já o direito de vizinhança são as regras que limitam o direito de propriedade a fim de evitar conflitos entre proprietários de prédios contíguos, respeitando, assim, o convívio social. Constituem obrigações propter rem (que acompanham a coisa) (Gonçalves, 2007).

Segundo Ulhoa (2012), o direito sobre a propriedade sofre restrições, na medida em que o proprietário deve exercê-lo de maneira condizente com o ordenamento jurídico; podendo, até mesmo, privar-lhe de exercer este direito em prol de um interesse de maior envergadura, por afetar um número considerável de pessoas, indistintamente, ou a própria sociedade.

O art. 1.277 do Código Civil estabelece que "o proprietário ou o possuidor de um prédio tem o direito de fazer cessar as interferências prejudiciais à segurança, ao sossego e à saúde dos que o habitam, provocadas pela utilização de propriedade vizinha"

Entende Tartuce (2020) que o condômino deve dar às suas partes a mesma destinação que tem a edificação, e não as utilizar de maneira prejudicial ao sossego, salubridade e segurança dos demais condôminos.

Em outras palavras, as características da propriedade serão preservadas desde que não ultrapassem os limites legais e morais, nem prejudiquem direitos coletivos e sociais, oportunidade na qual lhes serão impostas restrições, podendo vir a ser considerado abusivos os atos que causem incômodo aos vizinhos.

Nesse contexto, a decorrência da aplicação dos direitos de vizinhança sobre a propriedade é, em síntese, a proibição de atitudes que, levando-se em conta a natureza e localização do imóvel, extrapolem o limite de tolerância dos demais moradores de um condomínio. 


\subsection{Condomínio Edilício e Normas Condominiais}

O Condomínio Edilício está definido no art. $1^{\circ}$ da lei 4591/64, senão vejamos: "As edificações ou conjuntos de edificações, de um ou mais pavimentos, construídos sob a forma de unidades isoladas entre si, destinadas a fins residenciais ou não residenciais, poderão ser alienados, no todo ou em parte, objetivamente considerados, e constituirá, cada unidade, propriedade autônoma sujeita às limitações desta lei."

Para Egito (2019), a palavra condomínio, refere-se a uma comunhão de direitos e deveres, com interesse sobre um determinado bem, que ocorre quando existe um domínio de mais de uma pessoa simultaneamente de uma determinada coisa. É uma copropriedade, onde existem diversos titulares de direitos sobre o determinado bem.

Segundo Penteado (2014), pode-se dizer que o condomínio em unidades autônomas parte da premissa da existência de algumas unidades imobiliárias independentes; enquanto outras áreas compreendidas no complexo condominial continuam sendo de uso comum e de propriedade em fração ideal (por quinhão).

Rizzardo (2015) define condomínio edilício como a copropriedade numa edificação da qual constam unidades privativas autônomas, de uso exclusivo, e partes que são propriedade comum dos condôminos.

De acordo com Farias e Rosenvald (2015), o condomínio edificado decorre de três atos distintos: instituição, convenção e regimento interno. A instituição é um ato preliminar pelo qual nasce efetivamente o condomínio, ao tempo em que a convenção e o regimento interno são atos originados de um condomínio já existente e responsáveis por disciplinar a sua existência e o seu funcionamento regular.

A simples instituição do condomínio não é capaz de satisfazer as suas regras de convivência, pois o ato de sua criação não antevê os inúmeros problemas que podem ocorrer em um edifício, razão pela qual se faz necessária a edição de normas que balizem a convivência dos condôminos, quais sejam, a convenção e regimento interno, que orientam condutas e versam sobre a aplicação de sanções a condôminos transgressores.

Nesse contexto, após a instituição do condomínio edilício, deverá ser disciplinada as relações internas entre os condôminos, o que ocorre por meio da convenção condominial e pelo regimento interno, que estabelecem os direitos e deveres dos condôminos, multas a serem aplicadas em caso do cometimento de infrações, os deveres do síndico e do conselho, dentre outros.

Magalhaes (2018), define a convenção como "uma lei básica do condomínio, estatuto que prevê, na regularidade da vida condominial, regras para as relações internas entre todos os condôminos e destes com o condomínio edilício"

Para Teixeira (2018), a convenção condominial é o documento que reúne as principais regras de convivência e de administração do condomínio. É a convenção que determina como o condomínio deverá ser gerenciado, organizando a vida no local e o trabalho do síndico.

De acordo com Simão e Kairalla (2019), a convenção de condomínio é, por via de consequência, responsável por estabelecer as sanções aos comportamentos indesejados dos condôminos, que vincula aqueles que a ela aderiram e que poderá ser oponível contra terceiros, desde que registrada no Registro de Imóveis.

O artigo 1.333, do Código Civil, estabelece que:

“Art. 1.333. A convenção que constitui o condomínio edilício deve ser subscrita pelos titulares de, no mínimo, dois terços das frações ideais e torna-se, desde logo, obrigatória para os titulares de direito sobre as unidades, ou para quantos sobre elas tenham posse ou detenção. Parágrafo único. Para ser oponível contra terceiros, a convenção do condomínio deverá ser registrada no Cartório de Registro de Imóveis."

Em uma análise ao disposto no Código Civil, a convenção condominial é um documento escrito que somente terá validade e eficácia jurídica se subscrita por, pelo menos, $2 / 3$ dos titulares das frações ideais do condomínio, tornando-se 
obrigatória para todas as pessoas que ocupam o edifício, tendo elas assinado ou não, bem como para aquelas que futuramente ingressarão no prédio, seja na condição de adquirente, locatário, ou promissário comprador, devido à força coercitiva desse instrumento normativo.

Nesse sentido estabelece a Súmula 260 do STJ: “A convenção de condomínio aprovada, ainda que sem registro, é eficaz para regular as relações entre os condôminos."

Já o regimento interno, conforme dispõe o art. 1334, V do Código Civil, será determinado pela Convenção Condominial, podendo integrar a Convenção ou ser formulado em momento posterior, tendo a função de complementar a Convenção Condominial.

O regimento interno reúne as normas mais básicas de convivência que afetam o dia a dia e os relacionamentos entre moradores, como questões sobre vagas de estacionamento, uso da piscina e salão de festas e horário de silêncio, buscando diminuir atritos e desentendimentos (Teixeira, 2018)

Nesse passo, podemos concluir que a convenção é a principal norma do condomínio edilício, estando hierarquicamente acima de qualquer outra, como o regimento interno que complementa a convenção no tocante à situações mais corriqueiras, decisões das assembleias ou resoluções do conselho consultivo, que são normas, que somente possuem eficácia jurídica quando se compatibilizam com a convenção, destacando que todos os documentos mencionados trabalham em conjunto para manter a paz e a harmonia na vida condominial.

\subsection{Condômino Antissocial}

De acordo com o dicionário Houaiss (Houaiss e Villar, 2001), "antissocial" pode ser definido como aquele contrário aos costumes, ideias ou interesses da sociedade, como aquele que viola as regras da vida em sociedade e da moral social. Já o dicionário Aurélio (Ferreira, 1999) conceitua "antissocial” como "Contrário à organização da sociedade como tal, ou que se opõe à ordem social vigente" (como citado em Moreira, 2015, pag. 08).

O comportamento em desacordo com os deveres de convivência e de boa vizinhança merece ser coibido, sendo, inclusive, um dos deveres do síndico de coibir a prática de infrações e violação aos direitos no condomínio. Tal premissa está disposta em nosso ordenamento no art. 1.337 do Código Civil, que prescreve que o condômino que infringir de forma reiterada as normas internas do condomínio ou regras básicas de boa vizinhança, poderá ser sancionado com multa, de até o décuplo do valor atribuído à contribuição condominial.

Segundo Paschoal (2014), o legislador, porém, não se preocupou em definir o significado de comportamento antissocial, fazendo uso das chamadas "cláusulas abertas", que são termos vazios e abstratos que demandam construção doutrinária e jurisprudencial para limitar o seu verdadeiro significado e extensão.

Importante destacar que a expressão "condômino antissocial" não existe na legislação razão pela qual não existe entendimento pacífico na sociedade, no meio jurídico, e doutrinário, quanto às condutas definidas como antissociais, dependendo da situação fática para determinar se houve ou não a sua configuração.

Para Rizzardo (2021), condômino antissocial é aquele que não tem um comportamento compatível com a vida em condomínio, que não respeita as limitações naturais dos edifícios coletivos, que viola os mais comezinhos princípios de convivência social.

De acordo com Farias e Rosenvald (2012), o condômino que não se adapta a vida em condomínio assume uma postura incompatível com as regras do instituto jurídico e mesmo com sanções aplicadas para que fossem observadas as normas condominiais, o morador continua a ofender bens econômicos e causar situações desagradáveis aos imóveis e moradores vizinhos, enquadra-se na figura de condômino antissocial.

Em outras palavras, conduta antissocial se caracteriza tanto pelo descumprimento das regras de convivência dispostas 
na convenção ou regimento interno do condomínio, como pela prática de condutas incompatíveis com a harmonia condominial, mesmo que não regulamentadas, sendo o condômino antissocial, portanto, o indivíduo que possui condutas incompatíveis com o direito de vizinhança, perturbando a paz condominial, prejudicando a segurança, a tranquilidade, o sossego, a saúde e o equilíbrio psíquico, social e econômico dos demais compossuidores.

Por todo exposto, embora não conste na lei a definição de conduta antissocial ou de condômino antissocial, o senso comum e a jurisprudência estabelecem que é o comportamento que não se coaduna com o que é socialmente esperado.

\subsection{Da possibilidade de exclusão do condômino antissocial}

A vida condominial, conforme acima exposto, exige o cumprimento das regras impostas pelo condomínio através da Convenção Condominial e Regimento Interno, assim como decisões assembleares e avisos expedidos pela administração, que estabelecem os direitos e deveres dos condôminos, como forma de preservar a harmonia e o bem-estar social, posto que condomínio edilício é caracterizado pela coexistência de partes comuns aos condôminos e de partes exclusivas de cada condômino (unidades autônomas).

O condômino que infringir as normas condominiais, deve, via de regra ser notificado previamente sobre a conduta praticada e em caso de reiteração, o condômino será multado. Caso a multa aplicada não surta efeito, o Código Civil, estabelece em seus artigos 1.336 e 1.337, uma gradação para aplicação das multas no caso de reincidência, podendo a multa alcançar o patamar ao décuplo do valor da cota condominial, pelo reiterado comportamento antissocial.

Nesse passo, o cerne da questão a respeito da possibilidade de exclusão do condômino antissocial é a ausência de previsão na lei sobre tal possibilidade, no entanto, apesar da omissão na lei, a doutrina e a jurisprudência têm se encarregado de aclarar a questão.

Em razão do impasse sobre a possibilidade ou não de exclusão, surgiram duas correntes, uma contrária à exclusão e outra a favor da possibilidade de exclusão. A doutrina contrária à possibilidade de exclusão se fundamenta na ausência de previsão legal para tanto, tendo em vista que o nosso ordenamento jurídico prevê tão somente a aplicação de sanções pecuniárias em patamar gradativo e por entender que violaria o princípio da dignidade da pessoa humana e da solidariedade social.

O professor Flávio Tartuce (2002), entende pela impossibilidade de exclusão do condômino antissocial, tendo em vista a violação ao princípio da dignidade da pessoa humana e da solidariedade social, ambos previstos constitucionalmente. Assevera, também, que o Código Civil não prevê tal possibilidade, bem como a exclusão do condômino antissocial violaria a ordem pública, sob a ótica da constitucionalização do direito civil.

Tartuce (2014), descreve que a exclusão do condômino antissocial é uma medida exagerada, que não pode ser aceita diante da tendência da constitucionalização do direito civil, inadmitindo-se penas civis com limitações a direitos alheios.

Outra parte da doutrina considera que a exclusão do condômino antissocial pode ser considerado o único meio viável de assegurar o sossego, a segurança e a saúde dos vizinhos, sendo referida sanção a possibilidade de tutelar e proteger os interesses dos demais condôminos, em respeito do princípio da função social da propriedade, no qual o direito do coletivo se sobrepõe ao direito individual.

Sobre a possibilidade da exclusão do condômino antissocial do condomínio edilício, importante destacar o enunciado 508 da V Jornada de Direito Civil do Conselho da Justiça Federal, que assim dispõe:

Verificando-se que a sanção pecuniária mostrou-se ineficaz, a garantia fundamental da função social da propriedade (arts.5 $5^{\circ}$, XXIII, CF/1988 e 1.228, § 1. ${ }^{\circ}$, CC) e a vedação ao abuso do direito (arts. 187 e $1.228, \S 2 .^{\circ}$, CC) justific am a exclusão do condômino antissocial, desde que a ulterior assembleia prevista na parte final do parágrafo único do artigo 1.337 do Código Civil delibere a propositura de ação judicial com esse fim, asseguradas todas as garantias inerentes ao devido processo legal. 
A jurisprudência também vêm admitindo a exclusão do condômino antissocial diante da reiteração e da gravidade de seu comportamento. O Tribunal de Justiça do Estado Rio Grande do Sul, no julgamento do Agravo de Instrumento 70065533911, manteve a decisão interlocutória que deferiu a exclusão do condômino antissocial. No caso em tela, o relator narra que foram apresentadas pelo Condomínio provas documentais representadas por Registro de Ocorrências referentes à perturbação do sossego com marretadas na parede durante o período noturno, ameaçar de morte, xingar com palavras de baixo calão, aparecer desnudo na janela, agredir fisicamente com cuspidas e arremesso de ovos e objetos nos moradores, danificar a propriedade alheia quebrando os vidros das janelas das residências e furando pneus dos carros, dentre outras, veja-se:

AGRAVO DE INSTRUMENTO. AÇÃO DE EXCLUSÃO DE CONDÔMINO ANTISSOCIAL. TUTELA ANTECIPADA. DEFERIMENTO. POSSIBILIDADE. Verossimilhança dos fatos alegados, tendo em vista que o agravado comprova, de forma inequívoca, o comportamento antissocial do demandado a impedir a convencia pacífica com os demais moradores. Receio de dano irreparável ou de difícil reparação, uma vez que a permanência do réu no condomínio coloca em risco à segurança e à integridade dos demais moradores. Manutenção da decisão que deferiu a tutela antecipada de exclusão do condômino, nos termos do art. 273, I, do CPC. NEGARAM SEGUIMENTO ao recurso, por decisão monocrática. (Agravo de Instrumento No 70065533911, Décima Oitava Câmara Cível, Tribunal de Justiça do RS, Relator: Nelson José Gonzaga, Julgado em 13/08/2015).

Em uma análise à jurisprudência acima, verifica-se que é possível a remoção judicial do condômino antissocial em casos graves, nos quais as condutas gravosas tenham persistido mesmo após a aplicação de multas gradativas, sendo portanto uma medida excepcional admitida pela doutrina e jurisprudência, apesar de não existir tal possibiliadde na lei.

O Tribunal de Justiça de São Paulo, por sua vez, asseverou no julgamento da apelação nº 0.280.101-94.2010.8.26.0000: "Para impor multa a condômino por reiterado comportamento antissocial exige-se, do síndico, notificação com descrição objetiva do fato que corresponda ao comportamento nocivo, além de prazo razoável para defesa. Exige-se, mais, 'ulterior deliberação da assembléia' com quórum 'de três quartos dos condôminos restantes'. Ausentes tais requisitos formais, anula-se a sanção imposta, repelindo-se, antes, as preliminares."

Corroborando desse entendimento, para Gagliano e Filho (2020), é de fundamental importância, sob pena de nulidade, que o condômino dito antissocial possa exercer o seu direito ao contraditório e ampla defesa, inclusive podendo estar acompanhado por seu advogado na assembleia condominial convocada para deliberar sobre sua expulsão.

Dessa forma, excepcionalmente, nas situações em que a multa aplicada com a devida observância ao contraditório, não surtir efeito prático, a jurisprudência têm admitido a exclusão do condômino antissocial, após cumprimento de todos os trâmites, quais sejam, realização da notificação, aplicação de multa, majoração da multa com a observância do contraditório e votação em assemblea sobre a possível exclusão do condômino antossocial.

\section{Conclusão}

Após abordagem das vertentes sobre o tema, que é polêmico e objeto de muitas discussões, especialmente, em razão da omissão da lei quanto à possibilidade ou impossibilidade de exclusão de um morador do condomínio edilício, surgiram duas correntes doutrinárias, quais sejam, a que admite e a que não admite essa possiblidade.

A primeira corrente considera que a propriedade não é um direito absoluto, em razão da função social, da garantia dos direitos coletivos e da vedação ao abuso do direito, para justificar a retirada do morador considerado antissocial do condomínio, impedindo-o de usar e habitar a sua unidade imobiliária. Já a segunda corrente fundamenta-se na ausência de previsão legal e na violação do direito de propriedade para rejeitar a expulsão.

Contudo, atualmente, o entendimento favorável à exclusão do condômino antissocial tem se mostrado ser o mais adequado e vem sendo adotado por muitos juízes e doutrinadores, em garantia do interesse coletivo e social, sendo tratada como uma medida excepcional, que somente poderá ser tomada quando as infrações se tornarem insuportáveis e a multa de 10 (dez) 
vezes o valor da taxa condominial imposta ao condômino não gerar mudanças em seu comportamento nocivo.

A exclusão do condômino deve ser entendida como a última alternativa capaz de cessar definitivamente os abusos do direito, as violações à função social da propriedade e de reestabelecer a harmonia e sossego dos demais compossuidores do condomínio edilício.

Espera-se que a questão objeto do presente estudo seja enfrentada pelas Cortes Superiores, a fim de que seja uniformizada a jurisprudência nos Tribunais, o que por consequência, proporcionará maior segurança jurídica aos cidadãos residentes em condomínio e aos aplicadores do direito.

Por todo o exposto, o condomínio edilício possui a possibilidade de excluir o condômino considerado antissocial, quando as multas aplicadas não surtirem efeitos para coibir o mal comportamento do condômino, desde que observado o contraditório e os trâmites necessários.

\section{Referências}

Almeida, M. B. (2017). Noções básicas sobre Metodologia de pesquisa científica. Universidade Federal de Minas Gerais. $<$ http://mba.eci.ufmg.br/downloads/metodologia.pdf

Brasil. Congresso Nacional. Código Civil, Lei ordinária federal n. $\quad$ o 10.406 , de $10 \quad$ de janeiro de 2002. http://www.planalto.gov.br/ccivil_03/leis/2002/110406compilada.htm

Brasil. Conselho da Justiça Federal. V Jornada de Direito Civil. Enunciado 508. https://www.cjf.jus.br/enunciados/enunciado/577

Brasil. Superior Tribunal de Justiça. Súmula 260. A convenção de condomínio aprovada, ainda que sem registro, é eficaz para regular as relações entre os condôminos. Brasília, DF: Superior Tribunal de Justiça, 2001.

Brasil. Tribunal de Justiça do Rio Grande do Sul. AI: 70065533911 RS, Relator: Nelson José Gonzaga, Data de Julgamento: 13/08/2015, Décima Oitava Câmara Cível, Data de Publicação: Diário da Justiça do dia 14/08/2015. https://tj-rs.jusbrasil.com.br/jurisprudencia/219768352/agravo-de-instrumento-ai-70065533911rs

Brasil. Tribunal de Justiça de São Paulo. Dir. Priv., Ap. Cív nº 0.280.101-94.2010.8.26.0000, Rel. Des. Celso Pimentel, Julg 14.12.2010.

Coelho, F. U. (2012). Curso de Direito Civil: direito das coisas. (4a ed.), Saraia, 4.

Egito, F. M. (2019) O condômino antissocial. https://franciscoegito.adv.br/blog/2016/10/o-condomino-antissocial.html

Farias, C. C. \& Rosenvald, N. (2012). Curso de direito civil: direitos reais. (8a ed.), JusPODIVM, 5.

Farias, C. C. \& Rosenvald, N. (2015) Curso de direito Civil. (11a ed.), Atlas.

Ferreira, A. B. de H. (1999). Novo Aurélio século XXI: o dicionário da língua portuguesa. Nova Fronteira.

Glagliano, P. S., \& Filho, R. P. (2021) Novo curdo de direito civil 5: direito reais.: Saraiva Educação.

Gonçalves, C. R. (2007) Direito Civil Brasileiro - Direito das coisas. volume V, editora Saraiva, $2^{\circ}$ tiragem.

Gonçalves, C. R. (2016) Direito Civil Brasileiro: Direito das Coisas. (11a ed.), Saraiva, 5.

Houaiss, A \& Villar, M. (2001) Dicionário Houaiss da língua portuguesa. Objetiva.

Magalhaes, R. S. de O. (2018) Relações de vizinhança no condomínio edilício. Conteúdo Jurídico. http://www.conteudojuridico.com.br/?artigos\&ver=2.590348\&seo=1.

Marconi, M. de A. \& Lakatos, E. M. (2002) Técnicas de Pesquisa: planejamento e execução de pesquisas, amostragens e técnicas de pesquisa, elaboração, análise e interpretação de dados. (5a ed.), Atlas.

Moreira, D. M. M. (2015) A exclusão do condômino antissocial no condomínio edilício. Rio de Janeiro. https://www.emerj.tjrj.jus.br/paginas/trabalhos_conclusao/1semestre2015/pdf/DanieleMaghellyMenezesMoreira.pdf

Paschoal, J. P. R. (2014) O Direito ao Sossego e o Condomínio Edilício. Revista Opinião Jurídica: Direito Imobiliário. Secovi-SP (Sindicato da Habitação), 2.

Penteado, L. de C. (2015) Direito das Coisas. (3a ed.), Revista dos Tribunais, 473.atual. Forense.

Rizzardo, A. (2015) Condomínio Edilício e Incorporação imobiliária. (4a ed.), Forense.

Rizzardo, A. (2021) Contratos. (19a ed.), Forense.

Simão, J. F., \& Kairalla, M. U. (2019). Impossibilidade de Exclusão do Condômino Antissocial. Revista Jurídica Luso-Brasileira, 5 (3), [967]-992 
Research, Society and Development, v. 11, n. 1, e33511124945, 2022

(CC BY 4.0) | ISSN 2525-3409 | DOI: http://dx.doi.org/10.33448/rsd-v11i1.24945

Tartuce, F (2002). Das penalidades no condomínio edilício. Análise das inovações do Código Civil de 2002. http://www.flaviotartuce.adv.br/artigos.

Tartuce, F. (2014) Manual de Direito Civil. (4a ed.), Método, 2014.

Tartuce, F. (2020). Direito Civil: teoria geral dos contratos e contratos em espécie. (15a ed.), Ed. Forence.

Teixeira, T. (2018) Convenção de condomínio: o que é e para que serve? https://blog.townsq.com.br/convencao-de-condominio-o-que-e-e-para-que-serve/ 